\author{
Renata MOLA ${ }^{1}$ \\ Michał CIEŚLIK ${ }^{2}$ \\ Joanna BARTOS ${ }^{3}$
}

\title{
ANALIZA STRUKTURY ZLACZA PA38/AZ31 WYTWORZONEGO METODĄ ZGRZEWANIA DYFUZYJNEGO
}

\begin{abstract}
W artykule przedstawiono analizę struktury złącza stop aluminium (PA38)-stop magnezu (AZ31) wytworzonego metodą zgrzewania dyfuzyjnego. Za pomocą mikroskopu optycznego i elektronowego mikroskopu skaningowego przeprowadzono szczegółowe badania metalograficzne. Skład chemiczny strefy złącza określono metodą mikroanalizy rentgenowskiej (EDS). Wykonano również pomiary mikrotwardości metodą Vickersa łączonych materiałów i strefy złącza. W wyniku procesu zgrzewania uzyskano trwałe połączenie. Strefa złącza, o grubości ok. $50 \mu \mathrm{m}$, miała budowę dwuwarstwową. Od strony stopu PA38 w złączu zidentyfikowano grubszą warstwę (ok. $40 \mu \mathrm{m}$ ) fazy międzymetalicznej $\mathrm{Al}_{3} \mathrm{Mg}_{2}$, od strony stopu AZ31 cieńszą warstwę (ok. $10 \mu \mathrm{m}$ ) fazy międzymetalicznej $\mathrm{Mg}_{17} \mathrm{Al}_{12}$. W mikrostrukturze strefy złącza od strony stopu PA38 na tle osnowy fazy $\mathrm{Al}_{3} \mathrm{Mg}_{2}$ stwierdzono obecność drobnych cząstek fazy $\mathrm{Mg}_{2} \mathrm{Si}$. Od strony stopu $\mathrm{AZ31}$, na tle fazy $\mathrm{Mg}_{17} \mathrm{Al}_{12}$, obserwowano lokalnie iglaste cząstki fazy Al-Mn-Si. Na podstawie pomiarów mikrotwardości stwierdzono, że strefa złącza zbudowana głównie z faz międzymetalicznych $\mathrm{Mg}$-Al charakteryzuje się kilkukrotnie wyższą mikrotwardością w porównaniu z łączonymi stopami.
\end{abstract}

Słowa kluczowe: stop magnezu, stop aluminium, strefa złącza, fazy międzymetaliczne, struktura, mikrotwardość

\section{Wprowadzenie}

Stopy metali lekkich, aluminium i magnezu są szeroko wykorzystywane w przemyśle motoryzacyjnym, maszynowym, zbrojeniowym, lotniczym i technice kosmicznej. Zastosowanie tych materiałów umożliwia obniżenie masy konstrukcji, a w konsekwencji zmniejszenie zużycia energii i paliw oraz ograniczenie poziomu emisji gazów cieplarnianych.

\footnotetext{
${ }^{1}$ Autor do korespondencji/corresponding author: Renata Mola, Politechnika Świętokrzyska, al. Tysiąclecia PP 7, 25-314 Kielce, tel.: 41 3424373, e-mail: rmola@tu.kielce.pl

${ }^{2}$ Michał Cieślik, Politechnika Świętokrzyska, e-mail: mcieslik@tu.kielce.pl

3 Joanna Bartos, Politechnika Świętokrzyska, e-mail: joanna_st_ce@o2.pl
} 
Stopy magnezu charakteryzują się niższą gęstością $\left(1,4-1,9 \mathrm{Mg} / \mathrm{m}^{3}\right)$ w stosunku do stopów aluminium (ok. $2,7 \mathrm{Mg} / \mathrm{m}^{3}$ ), wyższą wytrzymałością względną $\left(\mathrm{R}_{\mathrm{m}} / \rho\right)$, znacznie lepszą skrawalnością oraz większą zdolnością tłumienia drgań. Niektóre właściwości stopów magnezu są jednak wyraźnie gorsze w porównaniu z właściwościami stopów aluminium: mała wytrzymałość na rozciąganie w podwyższonej temperaturze i mała odporność na pełzanie oraz ograniczona podatność na odkształcenia plastyczne w temperaturze pokojowej. Stopy magnezu charakteryzują się także małą udarnością. Ponadto stopy te mają znacznie niższą odporność na korozję i ścieranie w porównaniu ze stopami aluminium [1-3].

$\mathrm{W}$ ostatnich latach obserwuje się zwiększone zainteresowanie tematyką wytwarzania bimetalowych wyrobów na bazie stopów magnezu i stopów aluminium. Dzięki unikatowym właściwościom, wynikającym z połączenia obu materiałów w jeden element konstrukcyjny, wyroby takie mogą stanowić atrakcyjny materiał do zastosowania w gałęziach przemysłu, gdzie duży nacisk kładzie się na redukcję masy konstrukcji. Do łączenia stopów magnezu ze stopami aluminium stosuje się następujące techniki: spawanie [4-6], lutowanie [7], zgrzewanie tarciowe [8-10], zgrzewanie wybuchowe [11], zgrzewanie dyfuzyjne [12-18], przeróbkę plastyczną [19-22] oraz metodę odlewniczą [23-25].

Technika zgrzewania dyfuzyjnego od lat jest stosowana do łączenia różnych metali i stopów [26-28]. Zgrzewanie dyfuzyjne opiera się na zjawisku wzajemnej dyfuzji materiałów łączonych (przy ich minimalnym plastycznym odkształceniu), nagrzanych do temperatury poniżej linii solidusu i znajdujących się w stanie ścisłego przylegania. Najczęściej proces jest realizowany w próżni lub w atmosferze gazów ochronnych. Podstawowymi parametrami zgrzewania dyfuzyjnego jest docisk, niezbędny do dobrego przylegania powierzchni łączonych materiałów, temperatura, w której intensywność procesów dyfuzyjnych jest dostatecznie duża, oraz czas trwania procesu konieczny do utworzenia złącza [29]. Z uwagi na specyfikę tej metody możliwe jest wytwarzanie złączy z materiałów, których nie można połączyć tradycyjnymi metodami. Z przeglądu literatury wynika, że prowadzone są badania nad zastosowaniem zgrzewania dyfuzyjnego do wytwarzania bimetalowych elementów na bazie metali lekkich: magnezu i aluminium [12-18]. $\mathrm{Z}$ prac badawczych dotyczących łączenia tą metodą czystych metali magnezu i aluminium wynika, że strefa złącza jest zbudowana $\mathrm{z}$ faz międzymetalicznych Mg-Al: ciągła warstwa fazy $\mathrm{Mg}_{17} \mathrm{Al}_{12}$ od strony $\mathrm{Mg}$, ciągła warstwa fazy $\mathrm{Al}_{3} \mathrm{Mg}_{2}$ od strony Al $[11,12,14]$. Podczas łączenia tą metodą stopów magnezu ze stopami aluminium składniki stopowe zawarte w łączonych materiałach mogą prowadzić do zasadniczych zmian w strukturze strefy złącza.

$\mathrm{W}$ prezentowanej pracy przedstawiono analizę struktury strefy złącza w bimetalowej próbce stop aluminium (PA38)-stop magnezu (AZ31), wytworzonej metodą zgrzewania dyfuzyjnego. W ramach eksperymentu przeprowadzono obserwacje struktury złącza na mikroskopie optycznym i elektronowym mikroskopie skaningowym oraz wykonano badania składu chemicznego metodą EDS. Dokonano również pomiarów mikrotwardości łączonych materiałów i strefy złącza. 


\section{Metodyka badań}

Bimetalowe złącza stop aluminium (PA38)-stop magnezu (AZ31) wytworzono metodą zgrzewania dyfuzyjnego. Skład chemiczny łączonych stopów przedstawiono w tab. 1. Oba stopy należą do grupy stopów do przeróbki plastycznej. Przygotowanie materiałów do badań przebiegało w opisany dalej sposób. Z płaskownika ze stopu PA38 o grubości $8 \mathrm{~mm}$ wycięto próbki o wymiarze 60x25 $\mathrm{mm}$, natomiast $\mathrm{z}$ wlewka stopu AZ31 wykonano próbki prostopadłościenne $60 \times 25 \times 12 \mathrm{~mm}$. Powierzchnie styku próbek przeszlifowano na papierach ściernych $\mathrm{SiC}$ do gradacji 800, następnie odtłuszczono w alkoholu etylowym i wysuszono. Proces zgrzewania prowadzono w piecu próżniowym firmy Czylok. Maksymalna temperatura pracy pieca wynosi $1200^{\circ} \mathrm{C}$. Piec jest wyposażony w tłoczysko, które ma wywierać nacisk na próbkę w trakcie procesu zgrzewania. Stanowisko do zgrzewania dyfuzyjnego i schemat procesu przedstawia rys. 1. Próbki PA38-AZ31 umieszczono w piecu i nagrzano do temperatury $420^{\circ} \mathrm{C}$ w czasie $20 \mathrm{~min}$, następnie wygrzewano $\mathrm{w}$ tej temperaturze przez $20 \mathrm{~min}$. Po procesie wygrzewania złącze było chłodzone z piecem do temperatury otoczenia. Podczas nagrzewania, wygrzewania i chłodzenia na próbkę PA38-AZ31 był wywierany nacisk $5 \mathrm{MPa}$.

Tabela 1. Skład chemiczny stopów

Table 1. Chemical composition of alloys

\begin{tabular}{|c|c|c|c|c|c|c|c|c|c|c|}
\hline \multirow{2}{*}{ Stop } & \multicolumn{10}{|c|}{ Pierwiastek stopowy, \% } \\
\cline { 2 - 13 } & $\mathrm{Al}$ & $\mathrm{Mg}$ & $\mathrm{Si}$ & $\mathrm{Fe}$ & $\mathrm{Zn}$ & $\mathrm{Mn}$ & $\mathrm{Cu}$ & $\mathrm{Cr}$ & $\mathrm{Ti}$ & $\mathrm{Ca}$ \\
\hline PA38 & reszta & 0,4 & 0,5 & 0,2 & 0,15 & 0,1 & 0,1 & 0,05 & 0,1 & - \\
\hline AZ31 & 3,1 & reszta & - & 0,005 & 0,8 & 0,7 & 0,05 & - & - & 0,04 \\
\hline
\end{tabular}

Przeprowadzono badania metalograficzne wytworzonych złączy. Bimetalowe próbki PA38-AZ31 przecinano w płaszczyźnie prostopadłej do powierzchni styku stop aluminium - stop magnezu. Obserwacje struktury strefy złącza utworzonej na granicy pomiędzy stopami zostały przeprowadzone na mikroskopie optycznym Nikon ECLIPSE MA200 i elektronowym mikroskopie skaningowym JEOL JSM-5400. Badania składu chemicznego strefy złącza przeprowadzono na mikroanalizatorze rentgenowskim EDS Link ISIS serii 300 Oxford Instruments sprzężonym z mikroskopem skaningowym. Mikrotwardość mierzono metodą Vickersa przy użyciu mikrotwardościomierza MATSUZAWA MMT. Zastosowano obciążenie $100 \mathrm{~g}$. 
a)

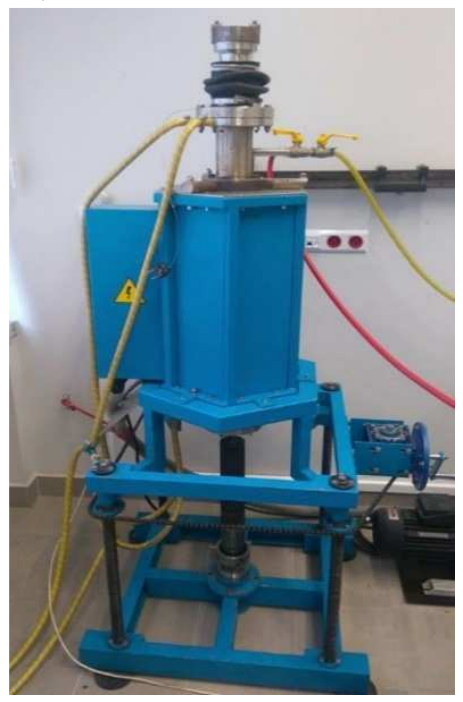

b)

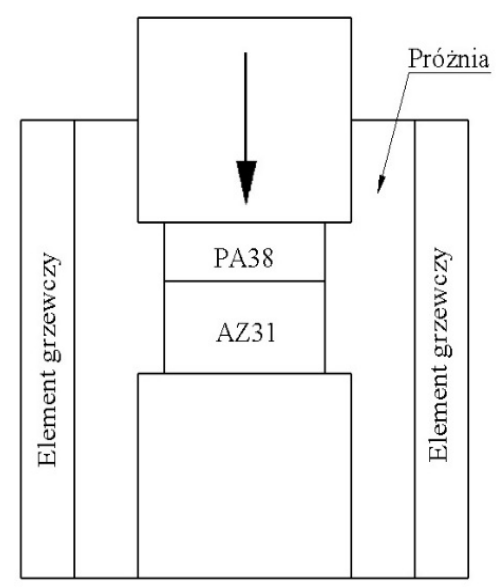

Rys. 1. Piec próżniowy firmy Czylok wyposażony w system docisku próbki (a), schemat procesu zgrzewania (b)

Fig. 1. Vacuum heat treatment furnace with an integrated pressing unit (a), schematic diagram of the diffusion bonding process (b)

\section{Wyniki badań}

Obraz struktury strefy złącza na granicy stop aluminium (PA38)-stop magnezu (AZ31), utworzonego w wyniku zgrzewania dyfuzyjnego, przedstawia rys. 2. W wyniku procesu wzajemnej dyfuzji pomiędzy stopami doszło do ich trwałego połączenia. Utworzona strefa złącza ma grubość ok. $50 \mu \mathrm{m}$.

a)

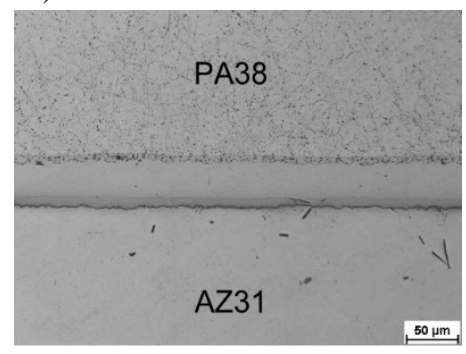

b)

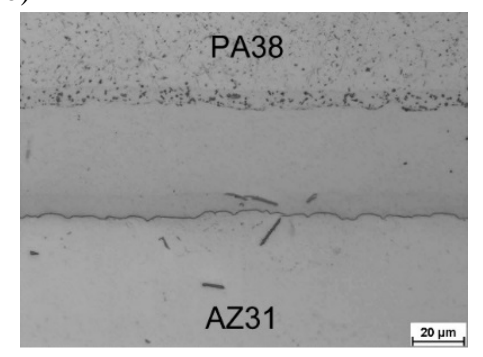

Rys. 2. Struktura strefy złącza w bimetalowej próbce PA38/AZ31 wytworzonej metodą zgrzewania dyfuzyjnego: (a) mniejsze powiększenie, (b) większe powiększenie (mikroskop optyczny)

Fig. 2. Structure of the bonding zone in the PA38/AZ31 bimetal specimen fabricated by diffusion bonding: (a) lower magnification, (b) higher magnification (optical microscope) 
Przeprowadzono szczegółową analizę struktury strefy złącza na mikroskopie skaningowym. Na rysunku 3. przedstawiono strukturę tej strefy w wybranych obszarach bimetalowej próbki wraz z analizą liniową. Produkty reakcji tworzą dwie warstwy. W strefie złącza od strony stopu PA38 można zaobserwować jaśniejszą, grubszą warstwę (ok. $40 \mu \mathrm{m}$ ), natomiast od strony stopu AZ31 - ciemniejszą, cieńszą warstwę o grubości ok. $10 \mu \mathrm{m}$. Analizując rozkład Mg i Al w wytworzonym złączu wzdłuż zaznaczonej linii, można zauważyć, że warstwa od strony stopu PA38 zawiera mniej Mg w porównaniu z warstwą obserwowaną od strony stopu AZ31. Wykonano analizy ilościowe w strefie złącza, a wyniki analiz punktowych zamieszczono w tab. 2. Stosunek ilości Mg:Al w procentach atomowych w grubszej warstwie od strony stopu PA38 (analiza ilościowa w punktach 1a i 1b - rys. 3.), zgodnie z układem równowagi fazowej Al-Mg [30], odpowiada składowi fazy międzymetalicznej $\mathrm{Al}_{3} \mathrm{Mg}_{2}$. W cieńszej warstwie od strony stopu AZ31 (analiza ilościowa w punktach $2 \mathrm{a}$ i $2 \mathrm{~b}$ - rys. 3.) wyniki analiz sugerują występowanie fazy międzymetalicznej $\mathrm{Mg}_{17} \mathrm{Al}_{12}$. Analiza ilościowa wskazuje na obecność cynku w tej fazie. $Z$ danych literaturowych wynika, że część atomów aluminium w fazie $\mathrm{Mg}_{17} \mathrm{Al}_{12}$ może być zastąpiona przez atomy cynku, dlatego faza ta jest często zapisywana jako $\operatorname{Mg}_{17}(\mathrm{Al}, \mathrm{Zn})_{12}$ [31].

a)
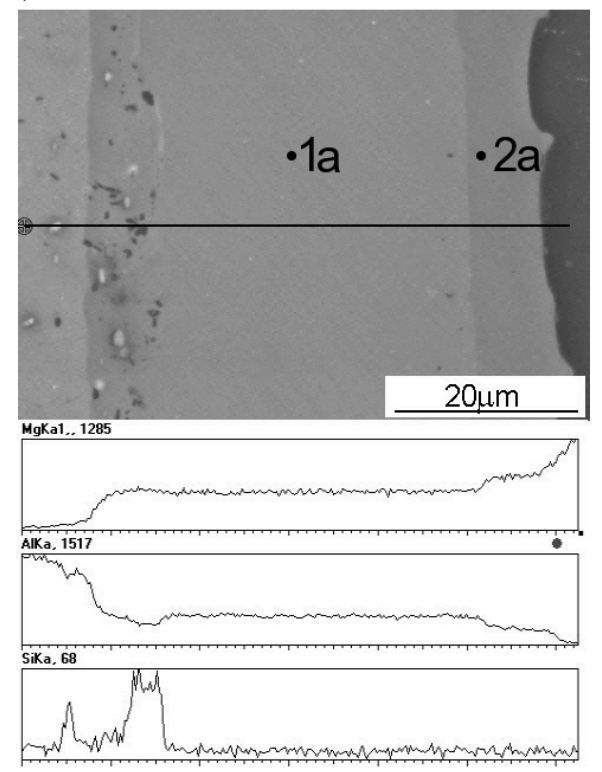

b)

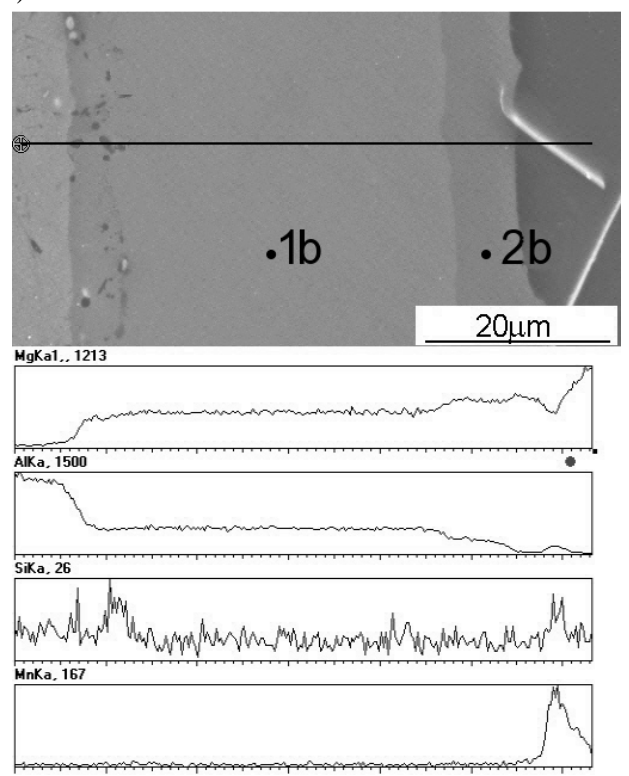

Rys. 3. Mikrostruktura złącza PA38/AZ31 wytworzonego metodą zgrzewania dyfuzyjnego wraz $\mathrm{z}$ analizą liniową pokazującą koncentrację $\mathrm{Mg}, \mathrm{Al}$, Si i Mn wzdłuż zaznaczonej linii

Fig. 3. Microstructure of the PA38/AZ31 joint fabricated by the diffusion bonding with concentration profiles of $\mathrm{Mg}, \mathrm{Al}, \mathrm{Si}$ and $\mathrm{Mg}$ along the marked line 
Tabela 2. Wyniki analizy ilościowej wykonanej metodą EDS w punktach oznaczonych na rys. 3 . Table 2. Results of the quantitative EDS analysis corresponding to the points marked in Fig. 3.

\begin{tabular}{|c|c|c|c|c|c|c|}
\hline \multirow{2}{*}{ Punkt } & \multicolumn{2}{|c|}{$\mathrm{Mg}$} & \multicolumn{2}{c|}{$\mathrm{Al}$} & \multicolumn{2}{c|}{$\mathrm{Zn}$} \\
\cline { 2 - 7 } & \% wag. & $\%$ at. & \% wag. & \% at. & \% wag. & \% at. \\
\hline 1a & 37,99 & 40,47 & 62,01 & 59,53 & - & - \\
\hline 1b & 37,26 & 39,72 & 62,74 & 60,28 & - & - \\
\hline 2a & 58,43 & 60,94 & 40,39 & 38,60 & 1,18 & 0,46 \\
\hline 2b & 59,19 & 59,72 & 41,69 & 39,84 & 1,12 & 0,44 \\
\hline
\end{tabular}

Analizując rozkład pierwiastków w strefie złącza (rys. 3.), można zaobserwować, że w warstwie fazy $\mathrm{Al}_{3} \mathrm{Mg}_{2} \mathrm{~W}$ sąsiedztwie stopu PA38 występują szare cząstki bogate w krzem. Na rysunku 4. przedstawiono szczegóły mikrostruktury tej warstwy obserwowane przy dużym powiększeniu na mikroskopie skaningowym. Wykonano analizy ilościowe dla kilku cząstek. Przykładowy skład chemiczny w \% atomowych był następujący: $60,48 \% \mathrm{Mg}, 38,64 \% \mathrm{Si}, 0,88 \%$ Al. Stosunek Mg:Si bliski 2:1 wskazuje, że są to cząstki fazy $\mathrm{Mg}_{2} \mathrm{Si}$. Cząstki tej fazy występują także w stopie PA38, ale znacznie więcej jest ich w strefie złącza w pobliżu stopu PA38 (rys. 3. i 4.). W stopie PA38 oraz w strefie złącza w jego pobliżu można także zaobserwować jasne, drobne cząstki. Skład chemiczny tych cząstek (przykładowy wynik analizy ilościowej w \% at.: 75,92 Al, 20,02 Fe, 4,06 $\mathrm{Si})$ wskazuje, że są to cząstki fazy bogatej w aluminium, żelazo i krzem. Na rysunku $3 \mathrm{~b}$ w strukturze stopu PA38 można zaobserwować białe, iglaste fazy. Rozkład liniowy pierwiastków świadczy o tym, że faza ta jest bogata w Al, Mn i Si. Lokalnie cząstki tej fazy można zauważyć także w strefie złącza od strony stopu PA31 (rys. 2b).

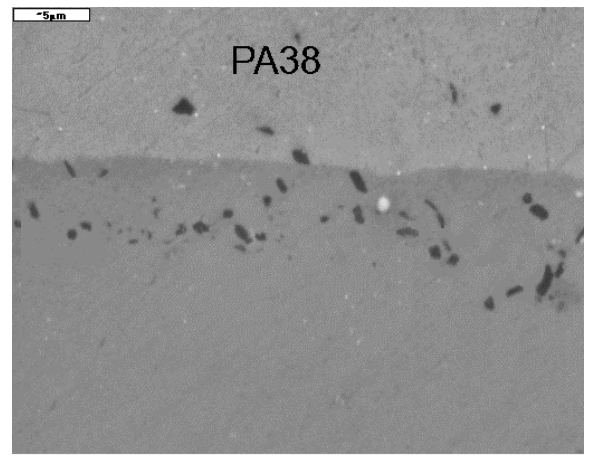

Rys. 4. Szczegóły mikrostruktury strefy złącza od strony stopu PA38

Fig. 4. Details of the microstructure of the bonding zone on the PA38 alloy side

Wykonano pomiar mikrotwardości bimetalowych próbek wytworzonych metodą zgrzewania dyfuzyjnego. Na rysunku 5. są widoczne ślady wgłębnika Vickersa w stopie PA38, strefie złącza i stopie AZ31. Wartości mikrotwardości uzyskane dla stopu aluminium PA38 mieściły się w granicach 32-33,9 HV0,1. 
Mikrotwardość stopu magnezu AZ31 była następująca: 45,5-47,7 HV0,1. W strefie złącza zbudowanej głównie z faz międzymetalicznych Mg-Al uzyskano najwyższe wartości mikrotwardości: 245-260,5 HV0,1. Jak zaznaczono wcześniej, strefa złącza ma budowę dwuwarstwową. Na rysunku 5. można zaobserwować, że odciski wgłębnika Vickersa znajdują się w grubszej warstwie fazy $\mathrm{Al}_{3} \mathrm{Mg}_{2}$ od strony stopu PA38. Warstwa fazy $\mathrm{Mg}_{17} \mathrm{Al}_{12}$ od strony stopu AZ31 była zbyt cienka, aby udało się zmierzyć jej mikrotwardość.

Rys. 5. Ślady odcisków wgłębnika Vickersa po pomiarach mikrotwardości w stopie PA38, strefie złącza i stopie AZ31

Fig. 5. Indentations left in the PA38 alloy, in the bonding zone and the AZ31 alloy after the Vickers microhardness test

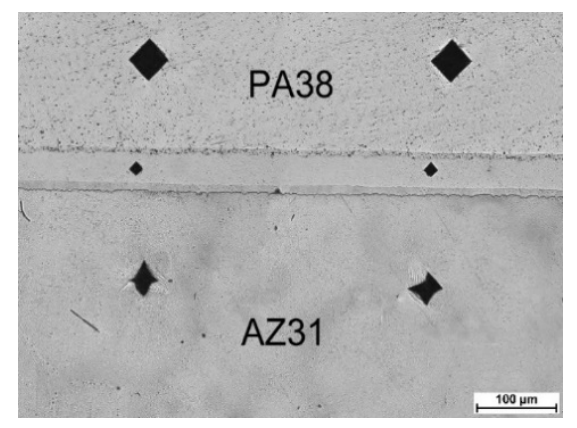

\section{Podsumowanie}

W wyniku procesu zgrzewania dyfuzyjnego prowadzonego w następujących warunkach: temperatura $420^{\circ} \mathrm{C}$, czas 20 min, docisk $5 \mathrm{MPa}$, uzyskano trwałe połączenie pomiędzy stopem aluminium PA38 a stopem magnezu AZ31. Strefa złącza miała grubość ok. $50 \mu \mathrm{m}$. Szczegółowe badania tej strefy przeprowadzone na elektronowym mikroskopie skaningowym wykazały jej warstwową budowę. Od strony stopu PA38 zidentyfikowano warstwę fazy $\mathrm{Al}_{3} \mathrm{Mg}_{2}$, a od strony stopu AZ31 - warstwę fazy $\mathrm{Mg}_{17} \mathrm{Al}_{12}$. W mikrostrukturze strefy złącza od strony stopu PA38 na tle osnowy fazy $\mathrm{Al}_{3} \mathrm{Mg}_{2}$ stwierdzono obecność drobnych cząstek fazy $\mathrm{Mg}_{2} \mathrm{Si}$. W strefie złącza od strony stopu AZ31, na tle osnowy fazy $\mathrm{Mg}_{17} \mathrm{Al}_{12}$, obserwowano lokalnie iglaste cząstki fazy Al-Mn-Si. Na podstawie pomiarów mikrotwardości stwierdzono, że strefa złącza charakteryzuje się kilkukrotnie wyższą mikrotwardością $\mathrm{w}$ porównaniu z łączonymi stopami. Mikrotwardość stopu aluminium PA38 zawierała się w przedziale 32-33,9 HV0,1. Dla stopu magnezu AZ31 uzyskano wartości mikrotwardości 45,5-47,7 HV0,1. Strefa złącza zbudowana głównie $\mathrm{z}$ faz międzymetalicznych $\mathrm{Mg}$-Al posiadała mikrotwardość 245-260 HV0,1.

\section{Literatura}

[1] Dziadoń A.: Magnez i jego stopy, Wydawnictwo Politechniki Świętokrzyskiej, Kielce 2012.

[2] Dziadoń A., Mola R.: Magnez - kierunki kształtowania własności mechanicznych, Obróbka Plastyczna, 24 (2013) 253-277. 
[3] Musfirah A.H., Jaharah A.G.: Magnesium and aluminum alloys in automotive industry, J. Applied Sci. Research, 8 (2012) 4865-4875.

[4] Borrisutthekul R., Miyashita Y., Mutoh Y.: Dissimilar material laser welding between magnesium alloy AZ31B and aluminum alloy A5052-O, Sci. Technol. Advanced Mater., 6 (2005) 199-204.

[5] Zhang H.T., Song J.Q.: Microstructure evolution of aluminum/magnesium lap joints welded using MIG process with zinc foil as interlayer, Materials Letters, 65 (2011) 3292-3294.

[6] Hayat F.: The effects of the welding current on heat input, nugget geometry, and the mechanical and fractural properties of resistance spot welding on $\mathrm{Mg} / \mathrm{Al}$ dissimilar materials, Materials and Design, 32 (2011) 2476-2484.

[7] Liu L.M., Tan J.H., Zhao L.M., Liu X.J.: The relationship between microstructure and properties of $\mathrm{Mg} / \mathrm{Al}$ brazed joints using $\mathrm{Zn}$ filler metal, Materials Characterization, 59 (2008) 479-483.

[8] Morishige T., Kawaguchi A., Tsujikawa M., Hino M., Hirata T., Higashi K.: Dissimilar welding of Al and Mg alloys by FSW, Materials Trans., 49 (2008) 1129-1131.

[9] Sato Y.S., Park S.H.C., Michiuchi M., Kokawa H.: Constitutional liquation during dissimilar friction stir welding of Al and Mg alloys, Scripta Materialia, 50 (2004) 1233-1236.

[10] Kwon Y.J., Shigematsu I., Saito N.: Dissimilar friction stir welding between magnesium and aluminium alloys, Materials Letter, 62 (2008) 3827-3829.

[11] Mróz S., Stradomski G., Dyja H., Galka A.: Using the explosive cladding method for production of Mg-Al bimetallic bars, Arch. Civil Mech. Eng., 15 (2015) 317-323.

[12] Liu P., Li Y., Geng H., Wang J.: A study of phase constitution near the interface of $\mathrm{Mg} / \mathrm{Al}$ vacuum diffusion bonding, Materials Letters, 59 (2005) 2001-2005.

[13] Li Y., Liu P., Wang J., Ma H.: XRD and SEM analysis near the diffusion bonding interface of Mg/Al dissimilar materials, Vacuum, 82 (2008) 15-19.

[14] Mahendran G., Balasubramanian V., Senthilvelan T.: Developing diffusion bonding windows for joining AZ31B magnesium-AA2024 aluminium alloys, Materials Design, 30 (2009) 1240-1244.

[15] Dziadoń A., Mola R., Błaż L.: Formation of layered Mg-eutectic composite using diffusional process at the Mg-Al interface, Arch. Metall. Mater., 56 (2011) 677-684.

[16] Zhu B., Liang W., Li X.: Interfacial microstructure, bonding strength and fracture of magnesium-aluminum laminated composite plates fabricated by direct hot pressing, Mater. Sci. Eng. A, 528 (2011) 6584-6588.

[17] Dietrich D., Nickel D., Krause M., Lampke T., Coleman M.P., Randle V.: Formation of intermetallic phases in diffusion-welded joints of aluminium and magnesium alloys, J. Mater. Sci., 46 (2011) 357-364.

[18] Mola R.: Microstructure of AlSi17/Mg joints fabricated by diffusion bonding at different temperatures, 26 ${ }^{\text {th }}$ Int. Conf. Metallurgy and Materials, METAL 2017.

[19] Liu X.B., Chen R.S., Han E.H.: Preliminary investigation on the Mg-Al-Zn/Al laminated composite fabricated by equal channel angular extrusion, J. Mater. Proc. Technol., 209 (2009) 4675-4681. 
[20] Zhang X.P., Yang T.H., Castagne S., Wang J.T.: Microstructure; bonding strength and thickness ratio of $\mathrm{Al} / \mathrm{Mg} / \mathrm{Al}$ alloy laminated composites prepared by hot rolling, Mate. Sci. Eng. A, 528 (2011) 1954-1960.

[21] Binotsch C., Nickel D., Feuerhack A., Awiszus B.: Forging of Al-Mg compounds and characterization of interface, Procedia Eng., 81 (2014) 540-545.

[22] Wierzba A., Mróz S., Szota P., Stefanik A., Mola R.: The influence of the asymmetric ARB process on the properties of Al-Mg-Al multi-layer sheets, Arch. Metall. Mater., 60 (2015) 2821-2825.

[23] Bae J.H., Prasada Rao A.K., Kim K.H., Kim N.J.: Cladding of Mg alloy with Al by twin-roll casting, Scripta Materialia, 64 (2011) 836-839.

[24] Hajjari E., Divandari M., Razavi S.H., Emami S.M., Homma T., Kamado S.: Dissimilar joining of $\mathrm{Al} / \mathrm{Mg}$ light metals by compound casting process, J. Mater. Sci., 46 (2011) 6491-6499.

[25] Mola R., Bucki T., Dziadoń A.: Microstructure of the bonding zone between AZ91 and AlSi17 formed by compound casting, Arch. Foundry Eng., 17 (2017) 202-206.

[26] Włosiński W., Jakubowski J., Krajewski A., Woźniczka M.: Zgrzewanie dyfuzyjne stopów na bazie NiAl i Ni33Al ze stalą St3S, Przegląd Spawalnictwa, 77 (2005) 2-6.

[27] Ossowski M., Hudycz M., Wierzchoń T.: Struktura i właściwości kompozytów warstwowych: stop tytanu - fazy międzymetaliczne z układu Ti-Al. Przegląd Spawalnictwa, 79 (2007) 13-16.

[28] Szwed B., Konieczny M.: Influence of diffusion bonding parameters on the structure and properties of titanium and stainless steel joints with copper interlayer, J. Achiv. Mater. Manuf. Eng., 67 (2014) 21-25.

[29] Poradnik spawalniczy, WNT, Warszawa 1967.

[30] Okamoto H.: Al-Mg (Aluminum-Magnesium), J. Phase Equilibria, 19 (1998) 598.

[31] Braszczyńska-Malik K.: Precipitates of gamma- $\mathrm{Mg}_{17} \mathrm{Al}_{12}$ phase in $\mathrm{Mg}-\mathrm{Al}$ alloys, Magnesium alloys - design, Processing and Properties, Frank Czerwiński (ed.), InTech, 2011, pp. 95-112.

\section{STRUCTURAL ANALYSIS OF THE PA38/AZ31 JOINT FABRICATED BY DIFFUSION BONDING}

\footnotetext{
S u m m a r y

This paper presents the results of the microstructure investigation of the aluminium alloy (PA38) - magnesium alloy (AZ31) joint fabricated by diffusion bonding. The structure of the bonding zone was examined using optical microscopy and scanning electron microscopy. The chemical composition of the bonding zone was determined by energy dispersive $\mathrm{X}$-ray microanalysis. The microhardness measurements of the alloys and the bonding zone was also conducted. As a result of the diffusion bonding process the alloys were joined together. The bonding zone with a thickness of about $50 \mu \mathrm{m}$ had two-layer structure. In the bonding zone the thicker layer (about $40 \mu \mathrm{m}$ ) of $\mathrm{Al}_{3} \mathrm{Mg}_{2}$ intermetallic phase was observed on the PA38 alloy side. The thinner layer (about $10 \mu \mathrm{m}$ ) of $\mathrm{Mg}_{17} \mathrm{Al}_{12}$ intermetallic phase was observed on the $\mathrm{AZ} 31$ alloy side. In the area of the bonding zone close to the PA38 alloy fine particles of $\mathrm{Mg}_{2} \mathrm{Si}$ phase were found in the matrix of $\mathrm{Al}_{3} \mathrm{Mg}_{2}$. In the bonding zone close to the AZ31 alloy locally a needle-shaped particles of the Al-Mn-Si phase were observed over the $\mathrm{Mg}_{17} \mathrm{Al}_{12}$ phase matrix. The results of microhardness measurement revealed that
} 
the bonding zone composed mainly of $\mathrm{Mg}$ - $\mathrm{Al}$ intermetallic phases layers had much higher microhardness than the joined alloys.

Keywords: magnesium alloy, aluminium alloy, bonding zone, intermetallic phases, structure, microhardness

DOI: $10.7862 / \mathrm{rm} .2018 .31$

Przestano do redakcji: 23.04.2018

Przyjęto do druku: 29.06.2018 